\title{
In $\mathfrak{y} \mathfrak{a l t}$.
}

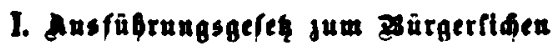
Gereq̧6udie.

Sttfungen. Qrtifel 1-4.

Anfall bes Bermögen eillez शiereinz ober eincr

Sttftung. Qurtitet 5 . . . . . . . . . . . . . 8

Erwerbobeiftäntungen fatr furititidie Berionen.

Irtitel 6, 7. . . . . . . . . . . . . 9

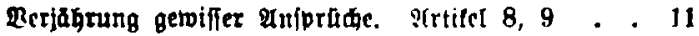

(Befeslide Binlen. Artitel $10 \ldots \ldots$. . . . . 18

BaGlungen aus offentligen saflen. Sirtitel 11 . 18

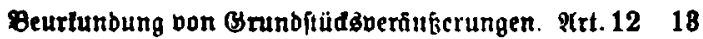

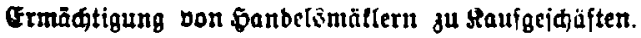

Irtilel 18 . . . . . . . . . . . 16

Gefinberedt. Ertitel 14 . . . . . . . . . 16

Leibgebingäbertrag. Artifel 15 . . . . . . 17

Staat81fulbbud. 2rtifel 16 . . . . . . . . . 21

Cकulbberffretbungen ouf ben 3ngaber. थrt. 17,18 22

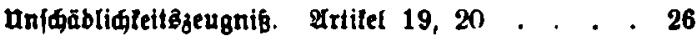

Eambethlturrenten. Ertitet 21 . . . . . . 27 


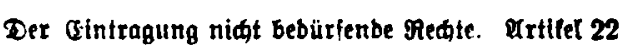

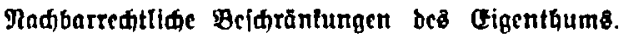

Artilel 23, 24

Biberruftides (Eigentl)um an Grumbitïden. 29rt. 25 31 Form ber \&uftafiung. Artitel 26. . . . . . . 32

Hebrrtragung bes Eigenthuma an buthungsitrcien

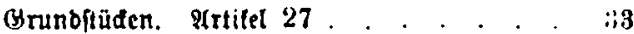

Bcitisidub bei Brunbbienftbarleiten. S(rtifel 28 . 39

2Bicberlaufōredt bei Rentengütern. Brtifel 29 , 84

Beiduränfung ber : iscnllaiten. Artilel 30 . . . 37

Bertgcilung von Reallaften. Arttel B1. . . . 38

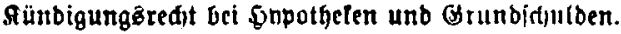

Irtitel 32 . . . . . . . . . . . . 38

Beftegende Eypotheten. Artitet 83 . . . . . . 89

Beftebenbe Brunblaulocr. Artilet 84 . . . . 42

uebcrtragung non Boridiften auf Rentenimulben.

Irtifel 86 . . . . . . . . . . . . 42

Euseinanberfegurgen. Qrtitel 86. . . . . . 48

Bergredt. Prtilel 37-89. . . . . . . . 48

Selbfắnbige Bercedtigleiten. erttlel 40. . . . 50

Bfantethgemerbe. Mrtitel 41 . . . . . . . 51

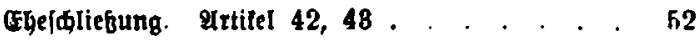

(Baterftanb beftegender GGen. Irtifel 44--67. . 54

Ertharungen thber ben Famillennamen. Artitel $68 \quad 83$ Glterlide Escwalt. Urtifel 69'. . . . . . . 85

Anerternung ber Baterfdaft. Artilet 70, 71 . . 87

Bcamte unb Beiftlide als Bormünber. 2rtitcl $72 \quad 88$

Priegunt von Manbelgelb. Irtitet 78-76. . 88

Bemcinbetwaifentath. Ertilet 77 . . . . . . 92 
Bebormunoung burt etnen Infaltsoorftanb ober

Eette

bush Beante ber Armenberwatturg. Art. $78 \quad 98$

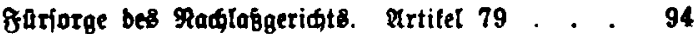

Rothteflament. Artilet 80 . . . . . . . . 94

Rmtlibe Berwahrung von Tejtantenten unb cro: verträgen. Urtilet 81 . . . . . . . . . 95

Erọfinung bon Teftamenten unb Erbbertragen.

Irtilfel 82 . . . . . . . . . . . . . . 97

Efptftelung bes (5ttragstwertbs cines ganoguts.

Urttlel 88 . . . . . . . . . . . . 97

finterlegung. Ortilel 84, 85 . . . . . . 97

Beridtôtoften. Artilet 86 . . . . . . . . 107

๔đlufbeftmmungen. Artifel 87-90 . . . . 188

II. Ansftiprungsgefet inu Eletisgelete

vou 17. gitat 1898, Betz. Aendernagen bet

glotfprojeforbunug.

Ertifel $1-8$

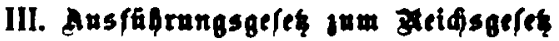

iber bie Bwangsverfteigerung und bie Bwangs. verwaftung.

Eriter Ab(d)nitt. Bivangóverfteigcrung und 3toang : verwaltung von Brunbfiuden im 2 Bege ber Bwangabonftredung. Frtilel $1-14$. . . 161 


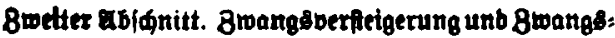

Seito

berwaltung pon BergmertsetgentGum, unbetoeg:

Iiden Bergmertsantheilen und felbftăndigen

Soblenabbau : Beredtigletten in goege ber

3wangs̄bouftredung. 2(rtitel 15-21

Dr:atur abjidnitt. Bwangêberitcigerung unb Bwangz: berwaltung in befonberen f̧ällen. Artifel 22-32 . . . . . . . . . . . . . 171

Bierter abfdititt. Edilub: unb ltevergangs:

beftimmungen. 2irtifel 33-48 . . . . . 17ó

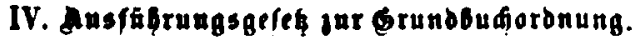

ârtitel 1-84 . . . . . . . . . . . . 187

\section{Fremfitides gelet \\ bber bie freiwifige bertitsbarkelt.}

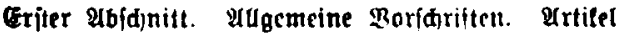
$1-18$. . . . . . . . . . 20 ?

3weiter थb/ artifel $19-28$. . . . . . . . . . . . . . 216

Dritter $\mathscr{Q}$ b f

Sdifieregifter unb sandrisfanten. Rrtilet 29,30 . . . . . . . . . . . . . 221

Bierter $\mathscr{R} b$ 低nitt. Beridtlide unb notariefle $u x=$ nunben. 
Erfitet Ittet. 3uftänbigtelt. Xrtifel $81-39$

228

Bwetter Iitel. urtunben über Heđ̆tx̄geiđäjte. Antifel 40-52 . . . . . . . . . 227

Tritter Zitel. Gonftige urfunden. \&rtitel 68 bis 62

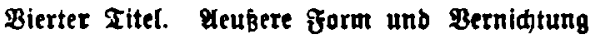
Der Urtunben. Rrtilel 68-65 . . . . . 286

Funfter Q geriळtliden Berfteigerung bon Grunbituden. Q Artitel 66-76 . . . . . . . . . . 288

Epdifter \&bidnitt. Amtsiftelung ber Rotare. Ertife! $77-108$

Siebenter \&bianitt. Befonbere Geriate. MRitwirfung ber Bemeinbebeamten in Ongelegengeiten ber

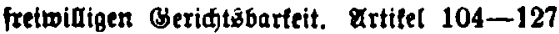

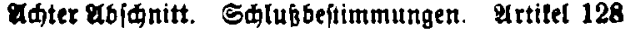

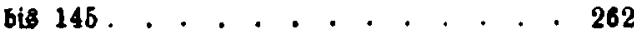

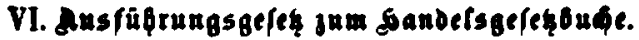
elrttlel $1-9$ 281

VII. Gefet, entpartend ote tanbesgefestiden Eor/driften Aber bie bebfifren ber gieds.

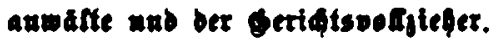

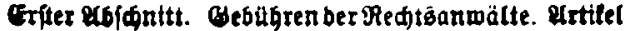
$1-17$ 
VIII Snbalt

3meiter Qubihnitt. Bebübren ber Beridtsooúzieger.

Selte Nrttlei $18-26$ 297

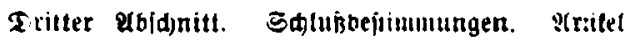

27-29. . . . . . . . . . . . . zyy

VIll. Ausfübrungsgelę zur ẹivilprojeforonung.

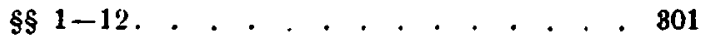

Eadtregifter. . . . . . . . . 307 